\title{
CONTEÚDO LIPÍDICO E PERFIL EM ÁCIDOS GRAXOS \\ DE FARELOS SUBMETIDOS À FERMENTAÇÃO POR Aspergillus oryzae EM ESTADO SÓLIDO
}

\author{
CRISTINAMOREIRADA SILVEIRA* \\ MELISSA DOS SANTOS OLIVEIRA** \\ ELIANA BADIALE-FURLONG***
}

\begin{abstract}
O objetivo deste trabalho foi analisar a variação no conteúdo lipídico e no perfil em ácidos graxos de farelo de arroz desengordurado (FAD) e de farelo de trigo (FT), submetidos à fermentação em estado sólido com o fungo Aspergillus oryzae. Amostras foram coletadas em intervalos de tempo de até 72 horas de fermentação. O teor de lipídios foi extraído pelo método de FOLCH e os ácidos graxos obtidos foram avaliados por cromatografia a gás. Os resultados mostraram que a fermentação não incrementou o teor de lipídios da biomassa, entretanto aumentou a incidência de ácidos graxos da série $\omega 6$.
\end{abstract}




\section{INTRODUÇÃO}

Farelos de arroz e de trigo são subprodutos abundantes do beneficiamento de cereais no estado do Rio Grande do Sul. Embora constituídos de altos teores de proteínas, lipídios e micronutrientes, ainda são pouco utilizados para o consumo humano devido às características sensoriais do farelo. Além disso, seu valor nutricional é questionável, especialmente pela disponibilidade de nutrientes e as condições sanitárias decorrentes do manejo inadequado, que gera produto de baixo valor comercial. O uso de farelo de arroz na agroindústria brasileira ocorre, principalmente, para extração de óleo que é rico em ácidos graxos insaturados. O farelo desengordurado resultante pode conter ao redor de 14\% de proteínas, $2 \%$ de lipídios, além de outros compostos químicos funcionais nem sempre disponíveis para o metabolismo humano (FEDDERN, BADIALE-FURLONG e SOUZA-SOARES, 2008; SILVEIRA B BADIALE-FURLONG, 2007).

$O$ farelo de trigo não se caracteriza como fonte de lipídios porque esses se encontram fortemente concentrados no gérmen, que é separado durante o processo de beneficiamento do cereal. Entretanto, apresenta em sua composição $14 \%$ de proteínas, $6 \%$ de cinzas, $60 \%$ de carboidratos, além de fibras e compostos funcionais (FEDDERN, BADIALE-FURLONG e SOUZA-SOARES, 2008; SILVEIRA e BADIALE-FURLONG, 2007). Uma alternativa para agregar valor a esses subprodutos seria utilizá-los como substrato em processo fermentativo, empregando espécies fúngicas que poderiam aumentar o nível de proteína digerível, propiciar maior aproveitamento de outros nutrientes por animais monogástricos, ou alterar seu perfil em ácidos graxos essenciais (PITT e HOCKING, 1997; PANDEY, 1992).

Os fungos são capazes de se desenvolver em condições variadas, o que resulta em alterações diversas, incluindo o perfil lipídico de diferentes substratos. A escassez de trabalhos com esse enfoque pode ser decorrente do fato de que fungos considerados seguros para consumo humano (GRAS), frequentemente empregados para estudos de processos fermentativos, não são caracteristicamente oleaginosos na maioria dos casos (ABU et al., 2000).

Durante a geração de biomassa fúngica, independentemente do substrato utilizado, os lipídios produzidos são predominantemente ácidos graxos representados principalmente pelos ácidos palmítico (C16:0), oleico (C18:1) e linoleico (C18:2) e alguns ácidos graxos de grande importância nutricional, como o ácido docosahexaenoico (DHA - C22:6). Os métodos descritos para determinar os lipídios de biomassa são semelhantes aos empregados para outras matrizes e consistem em sua extração empregando solventes orgânicos e sua conversão em ésteres metílicos de ácidos graxos, derivados voláteis, que podem ser analisados por cromatografia a gás (FAKAS et al., 2008; PENG e CHEN et al., 2008; ZHU, ZONG e WU, 2008; FAKAS et al., 2007; ABU et al., 2000; STREDANSKY, CONTI e SALARIS, 2000; STREDANSKY et al. 2000; CERTIK e SHIMIZU, 1999; ZIINO et al., 1999; NEMEC, JERNEJC e CIMERMAN, 1997).

Os métodos de extração com solventes orgânicos podem empregar calor, a exemplo do método de SOXHLET, ou extrair a frio, como é o caso dos métodos de FOLCH, LEES e STANLEY (1957) e do método BLIGH-DYER (1959).

Tendo em vista a importância do aproveitamento de subprodutos de cereais e sendo a fermentação processo aplicável para disponibilizar nutrientes, seria interessante verificar o efeito do desenvolvimento de biomassa fúngica no conteúdo lipídico e na composição em ácidos graxos durante esse processo.

O objetivo do presente trabalho foi estudar o melhor método para a extração de lipídios de biomassa fúngica e a partir de sua escolha extrair lipídios de farelos fermentados, durante diferentes tempos, e determinar variações no teor lipídico e no perfil em ácidos graxos durante fermentação em estado sólido utilizando o fungo Aspergillus oryzae.

\section{MATERIAL E MÉTODOS}

\subsection{CARACTERIZAÇÃO DA MATÉRIA-PRIMA}

O farelo de arroz desengordurado (FAD) e o farelo de trigo (FT) foram obtidos em agroindústrias da 
região sul do Rio Grande do Sul. Estabeleceu-se a granulometria entre 0,35 e 0,59 mm para emprego dos farelos como substrato nos processos fermentativos. A composição dos farelos foi determinada segundo métodos da AOAC (2000), exceto o conteúdo de fibras, estimado por diferença. Os farelos também foram submetidos à avaliação micotoxicológica, determinando-se a ocorrência de aflatoxinas $B_{1}, B_{2}, G_{1}$ e $G_{2}$, ocratoxina A e zearalenona, segundo método descrito por DORS, PINTO e BADIALEFURLONG (2009).

\subsection{PRODUÇÃO DE BIOMASSA}

O fungo Aspergillus oryzae foi inoculado em ágar batata dextrose e incubado em estufa com circulação de ar a $30^{\circ} \mathrm{C}$ durante 72 horas. Preparou-se solução de esporos contendo $2,4 \times 10^{5}$ esporos/ $\mathrm{mL}$. Aos farelos homogeneizados foi adicionada solução de nutrientes contendo $2,0 \mathrm{~g} / \mathrm{L}$ de $\mathrm{KH}_{2} \mathrm{PO}_{4}$, $1,0 \mathrm{~g} / \mathrm{L}$ de $\mathrm{MgSO}_{4}$ e 1,8 $\mathrm{g} / \mathrm{L}$ de uréia em $\mathrm{HCl} 800 \mathrm{mM}$ e água destilada estéril, a fim de ajustar a umidade para aproximadamente $50 \%$. Após, foram adicionados $11,5 \mathrm{~mL}$ da solução de esporos de Aspergillus oryzae de modo a se obter concentração de $4 \times 10^{6}$ esporos/g de meio. Os meios foram distribuídos em bandejas, constituindo camada uniforme de $1 \mathrm{~cm}$ de espessura. As bandejas foram mantidas em estufa de circulação de ar a $30^{\circ} \mathrm{C}$ durante 72 horas. Amostras foram coletadas no tempo zero e em intervalos de 24, 48 e 72 horas de fermentação.

As condições para a produção de biomassa foram adaptadas do trabalho de OLIVEIRA e BADIALE-FURLONG (2008).

\subsection{DETERMINAÇÃO DE LIPÍDIOS E PERFIL EM ÁCIDOS GRAXOS}

Os lipídios da biomassa fúngica e do fungo cultivado em ágar batata dextrose foram extraídos pelo método de FOLCH et al.(1957), utilizando-se clorofórmio e metanol (2:1) em funil de separação. Após a separação das fases e evaporação do solvente foram quantificados gravimetricamente.

Os ácidos graxos obtidos foram derivatizados para a obtenção de ésteres metílicos, segundo o método de METCALFE, SCHIMTZ e PELKA (1966), mediante adição de $5 \mathrm{~mL}$ de solução metanólica $500 \mathrm{mM}$ de $\mathrm{KOH}$, aquecimento por 7 minutos, adição de $1,5 \mathrm{~mL}$ da mistura de trifluoreto de borometanol (10\%), aquecimento por 15 minutos e extração com hexano.

Os ésteres metílicos de ácidos graxos foram analisados por cromatografia a gás, usando-se cromatógrafo Varian Star Chromatograph $3400 \mathrm{CX}$, equipado com coluna capilar de polietilenoglicol (DB-WAX $30 \times 0,32 \mathrm{~mm}$ e espessura de filme de 0,25 $\mu \mathrm{m}$ ). Programou-se a temperatura da coluna para variar entre 100 e $230^{\circ} \mathrm{C}$ a $8^{\circ} \mathrm{C} / \mathrm{min}$, sendo mantida a temperatura final por 20 minutos. As temperaturas do injetor e do detector foram $250^{\circ} \mathrm{C}$ e $280^{\circ} \mathrm{C}$, respectivamente, usando-se nitrogênio como gás de arraste com fluxo de $1,0 \mathrm{~mL} / \mathrm{min}$.

A identificação dos picos cromatográficos ocorreu pela comparação dos tempos de retenção de cada éster metílico de ácido graxo das amostras com os da mistura de padrões (SIGMA-SUPELCO 18919), sendo a quantificação efetuada pela normalização das áreas dos picos. Os resultados foram apresentados como \% de cada ácido graxo identificado na fração lipídica.

\subsection{ANÁLISE ESTATÍSTICA}

Para avaliar o efeito do tempo de fermentação e tipo de farelo no teor de lipídios e na composição em ácidos graxos saturados e insaturados empregou-se a análise de variância (ANOVA), sendo a diferença entre as médias de quatro repetições experimentais estimada pelo Teste de Tukey, ao nível de significância de $p<0,05$, utilizando-se o software o STATISTICA (2001). 


\section{RESULTADOS E DISCUSSÃO}

\subsection{CARACTERIZAÇÃO DA MATÉRIA-PRIMA}

A composição centesimal do farelo de arroz desengordurado e do farelo de trigo empregados como substratos pode ser vista na Tabela 1, com valores expressos em base seca.

\section{TABELA 1 - COMPOSIÇÃO CENTESIMAL DE FARELO DE ARROZ DESENGORDURADO (FAD) E DE FARELO DE TRIGO (FT) (IN NATURA)}

\begin{tabular}{ccc}
\hline Componente (\%) & FAD & FT \\
\hline Umidade & $9,2 \pm 0,07$ & $9,4 \pm 0,26$ \\
Proteínas & $19,2 \pm 0,31$ & $13,8 \pm 0,56$ \\
Lipídios & $5,7 \pm 1,66$ & $5,2 \pm 0,70$ \\
Carboidratos & $47,1 \pm 0,44$ & $60,1 \pm 2,28$ \\
Cinzas $^{*}$ & $11,7 \pm 1,10$ & $6,3 \pm 0,53$ \\
Fibras $^{*}$ & 7,1 & 5,2 \\
\hline
\end{tabular}

* conteúdo estimado por diferença.

A composição centesimal dos farelos apresentou-se conforme as determinações citadas por outros autores (FEDDERN, BADIALE-FURLONG e SOUZA-SOARES, 2008; CACCIAMANI et al., 2007), levando-se em conta as diferenças decorrentes do tipo de solo, da cultivar, do beneficiamento e da forma de estabilização dos mesmos.

O farelo de arroz desengordurado apresentou maior conteúdo de proteínas e cinzas em relação ao farelo de trigo ( $p=0,0002$ para os dois parâmetros), entretanto, o farelo de trigo apresentou maior conteúdo de carboidratos $(p=0,0002)$. Para os outros parâmetros componentes avaliados não houve diferença significativa.

A triagem de aflatoxinas $B_{1}, B_{2}, G_{1}$ e $G_{2}$, ocratoxina $A$ e zearalenona foi realizada em virtude dos relatos de contaminação de farelos e da possibilidade demonstrada de interferência das toxinas no desenvolvimento fúngico (CACCIAMANI et al., 2007). O método empregado para a determinação de micotoxinas tinha como limites de deteção $2,5 \mathrm{ppb}$ para aflatoxinas, 6,7 ppb para ocratoxina A e 47,0 ppb para zearalenona e recuperação média de $87 \%$ para cada micotoxina. Nessas condições não foi detectada a ocorrência de micotoxinas nos farelos.

\subsection{DETERMINAÇÃO DO CONTEÚDO LIPÍDICO}

Embora o método de SOXHLET seja oficial para determinação de lipídios, não foi adotado para a realização deste trabalho devido ao uso de altas temperaturas. Isso poderia favorecer maior incidência de ácidos graxos de configuração trans, o que não permitiria a distinção do efeito do processo fermentativo ou do método de extração. Para SILVEIRA et al. (2006) o método de FOLCH et al. (1957) é melhor para a extração de lipídios por ser realizada a frio, além de ser simples sob o ponto de vista operacional.

O teor de lipídos apresentado pela biomassa produzida por Aspergillus oryzae em ágar batata dextrose ao longo de 72 horas foi de $2,1 \%$.

$\mathrm{Na}$ Tabela 2 são apresentados os percentuais de lipídios totais contidos nos farelos fermentados durante 72 horas. 


\section{TABELA 2 - TEOR DE LIPÍDIOS DE FARELO DE ARROZ DESENGORDURADO (FAD) E FARELO}

DE TRIGO (FT) FERMENTADOS POR Aspergillus oryzae

\begin{tabular}{ccc}
\hline & \multicolumn{2}{c}{ Conteúdo lipídico (\%) } \\
\cline { 2 - 3 } Tempo & FAD & FT \\
\hline $0 \mathrm{~h}$ & $3,0^{\mathrm{a}}$ & $5,1^{\mathrm{b}}$ \\
$24 \mathrm{~h}$ & $2,9^{\mathrm{a}}$ & $4,8^{\mathrm{b}}$ \\
$48 \mathrm{~h}$ & $3,0^{\mathrm{a}}$ & $5,1^{\mathrm{b}}$ \\
$72 \mathrm{~h}$ & $3,1^{\mathrm{a}}$ & $4,6^{\mathrm{b}}$ \\
& & \\
\hline
\end{tabular}

Letras iguais indicam que não existe diferença significativa entre as médias quando aplicado o Teste de Tuckey ao nível de significância de $p<0,005$.

O teste de Tukey indicou que não existem diferenças significativas na fração lipídica de cada farelo fermentado durante os intervalos de tempo avaliados. Ao comparar o farelo de arroz desengordurado não fermentado e a amostra de farelo coletada no início da fermentação foi encontrada redução significativa no teor de lipídios $(p=0,0001)$. Tal fato pode ser explicado pela metodologia de extração empregada, uma vez que no farelo in natura os lipídios foram extraídos pelo método de SOXHLET (AOAC, 2000), enquanto nos farelos fermentados utilizou-se o método de FOLCH et al. (1957). Outra explicação para essa redução seria a formulação do meio com casca de arroz e solução de nutrientes, conforme apresentado em material e métodos.

Na literatura não foram encontradas referências relativas a estudos de perfil lipídico de farelos fermentados pela espécie fungica utilizada. Em outras matrizes fermentadas em estado sólido por Aspergillus oryzae foi observado incremento nos lipídios da biomassa, atingindo valor de 6 vezes ao inicial após 240 horas de processo ( $A B U$ et al, 2000). Sendo assim, o intervalo de fermentação adotado neste trabalho não foi suficiente para aumentar o teor lipídico da biomassa. Outro ponto que pode ter determinado a diferença é a composição do substrato.

\subsection{PERFIL EM ÁCIDOS GRAXOS}

O fungo Aspergillus oryzae cultivado em ágar batata dextrose apresentou o seguinte perfil em ácidos graxos: 26,0\% de ácido palmítico (C16:0); 1,0\% de ácido margárico (C17:0); 0,5\% de ácido esteárico (C18:0); 36,4\% de ácido oleico (C18:1 - $\omega 9 ; 34,1 \%$ de ácido linoleico (C18:2 - $\omega 6)$ e 0,2\% de ácido linolênico (C18:3 - $\omega 3$ ). A relação entre ácidos graxos saturados e insaturados foi de 0,39.

NEMEC, JERNEJC e CIMERMAN (1997) determinaram o perfil em ácidos graxos de diferentes gêneros de Aspergillus e encontraram para a espécie oryzae 16,1\% de ácido palmítico (C16:0), 0,7\% de ácido palmitoleico (C16:1), 0,4\% de ácido margárico (C17:0), 3,8\% de ácido esteárico (C18:0), 12,5\% de ácido oleico (C18:1), 58,0\% de ácido linoleico e 7,3\% de ácido linolênico. A relação saturados e insaturados foi de 0,26 .

FAKAS et al. (2008), analisando o perfil lipídico do fungo Cunninghamella echinulata, encontraram cerca de 20,0\% de ácido palmítico (C16:0), 10,0\% de ácido esteárico (C18:0), 40\% de ácido oleico (C18:1), 17,0\% de ácido linoleico (C18:2) e cerca de 13,0\% de ácido $\gamma$-linolênico (C18:3) para os diferentes substratos em que o fungo foi inoculado. Obtiveram relação entre saturados e insaturados de 0,43 .

ZHU, ZONG e WU (2008), analisando o perfil lipídico do fungo Trichosporpon fermentans, encontraram predominantemente os ácidos palmítico (C16:0), esteárico (C18:0), oleico (C18:1) e linoleico (C18:3). A relação saturados e insaturados foi de 0,56.

O perfil dos ácidos graxos presentes no farelo de arroz desengordurado e no farelo de trigo, fermentados e não fermentados está apresentado na Tabela 3. 


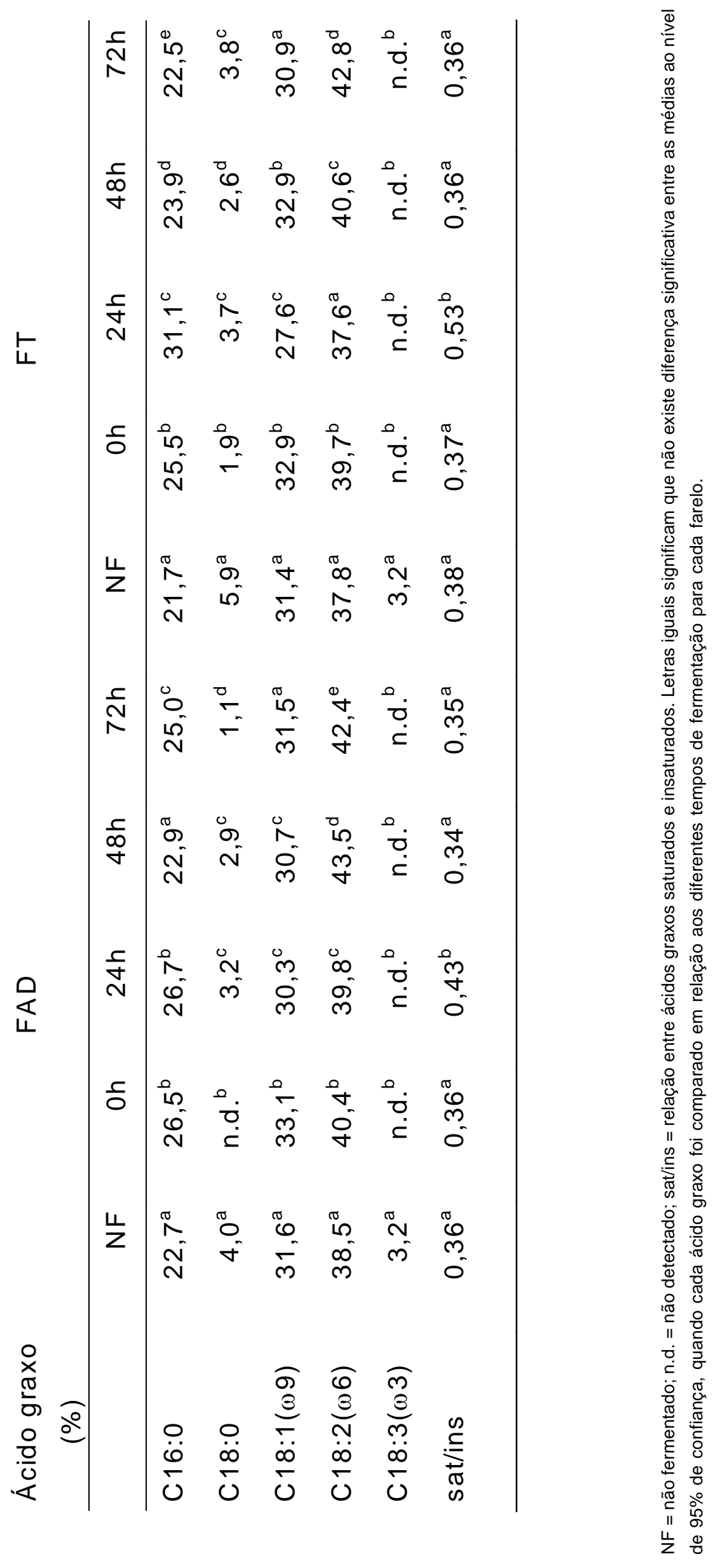




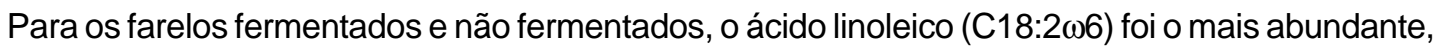

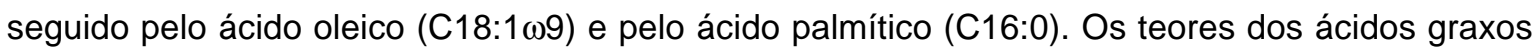
determinados variaram de 37 a 43\% para o ácido linoleico, de 27 a 32\% para o ácido oleico e de 22 a $31 \%$ para o ácido palmítico, aproximadamente.

É interessante destacar que o mesmo perfil em ácidos graxos foi observado para os dois farelos utilizados como substrato. Em comparação com o farelo não fermentado houve aumento significativo dos ácidos graxos palmítico (C16:0) e linoleico (C18:2), redução significativa dos ácidos esteárico (C18:0) e linolênico (C18:3), enquanto para o ácido oleico (C18:1) não houve variação significativa. Outra característica que pode ser destacada para os ácidos graxos da série $\omega 3$, representados neste estudo pelo ácido linolênico (C18:3), foi sua redução significativa, sendo que o mesmo foi detectado somente nos farelos não fermentados. Essa característica também foi verificada na biomassa fúngica produzida em meio de cultura. Para o ácido da série $\omega 6$, ácido linoleico (C18:2), houve aumento significativo durante a fermentação de 10 e 11\%, respectivamente, para farelo de arroz e farelo de trigo. Tal fato pode ser atribuído à característica metabólica do fungo, uma vez que na biomassa pura esse foi um dos ácidos graxos mais abundantes.

A relação entre ácidos graxos saturados e insaturados para os farelos mostrou aumento significativo em 24 horas de fermentação, sugerindo que na fase de desenvolvimento da biomassa (primeiras 24 horas) o fungo começa a utilizar seus lipídios para a formação de suas estruturas. Outra possibilidade é que a partir das 24 horas de fermentação as enzimas lipolíticas presentes nos farelos começam a atuar, cindindo as ligações duplas nos ácidos insaturados C18:2 e C18:1, transformando-os em C18:0.

\section{CONCLUSÃO}

O teor de lipídios dos farelos fermentados não variou ao longo do intervalo de fermentação estudado.

Os ácidos graxos linoleico, oleico e palmítico foram os predominantes nos farelos fermentados por Aspergillus oryzae. O perfil em ácidos graxos dos farelos fermentados em comparação com os farelos não fermentados mostrou alterações como, aumento significativo dos teores dos ácidos palmítico e linoleico e redução significativa dos ácidos esteárico e linolênico.

\section{ABSTRACT \\ LIPID CONTENT AND FATTY ACID PROFILE OF DEFATTED RICE BRAN AND WHEAT BRAN SUBMITTED TO SOLID STATE FERMENTATION BY Aspergillus oryzae}

The objective of this work was to analyze the alteration in lipid content and fatty acid profile in the defatted rice bran and wheat bran fermented by fungus Aspergillus oryzae in solid-state system. Samples were collected in intervals of $0,24,48$ and 72 hours of fermentation. The lipids extraction was conducted by FOLCH method and fatty acids obtained were analyzed by gas chromatography. The results showed that the fermentation caused no alteration in lipid content of biomass, however caused variation in the composition in fatty acids, increasing the incidence of the $\omega 6$ fatty acids for defatted rice bran and wheat bran in approximately 10 and $11 \%$, respectively.

KEY-WORDS: FUNGAL BIOMASS; NUTRIENTS; WASTES REUTILIZATION.

\section{REFERÊNCIAS}

1 ABU, O. A.; TEWE, O. O.; LOSEL, D. M.; ONIFADE, A. A. Changes in lipid, fatty acids and protein composition of sweet potato (Ipomoea batatas) after solid-state fungal fermentation. Bioresource Technology, v. 72, p. 189-192, 2000.

2 AOAC. Association of Official Analytical Chemists. Official methods of analysis of AOAC international. $17^{\text {th }}$ ed. Gaithersburg, 2000. 
3 BLIGH, E. G.; DYER, W. J. A rapid method of total lipid extraction and purification. Canadian Journal of Biochemistry and Physiology, v. 8, n. 37, p. 911-917, 1959.

4 CACCIAMANI, J. L.; PEREZ, G. L.; GARDA, J.; BADIALE-FURLONG, E. Efeito dos tratamentos térmicos seco e úmido nos níveis de aflatoxina B1 e ocratoxina A presentes em farelos e farinhas de cereais. Boletim do CEPPA, v. 25, p. 157-164, 2007.

5 CERTIK, M.; SHIMIZU, S. Biosynthesis and regulation of microbial polyunsaturated fatty acid production. Journal of Bioscience and Bioengineering, v. 87, n. 1, p. 1-14, 1999.

6 DORS, G. C.; PINTO, L. A. A.; BADIALE-FURLONG, E. Migration of mycotoxins into rice starchy endosperm during the parboiling process. LWT - Food Science and Technology, v. 42, n.1, p. 433-437, 2009.

7 FAKAS et al. Compositional shifts in lipids during lipids turnover in Cunninghamella echinulata. Microbial Technology, v. 40, p.1321-1327, 2007.

8 FAKAS et al. $\gamma$-linolenic acid production by Cunninghamella echinulata growing on complex organic nitrogen sources. Bioresource Technology, v. 99, p. 5986-5990, 2008.

9 FEDDERN, V.; BADIALE-FURLONG, E.; SOUZA-SOARES, L. A. Efeitos da fermentação nas propriedades físicoquímicas e nutricionais do farelo de arroz. Boletim da SBCTA, v. 27, p. 800-804, 2007.

10 FOLCH, J.; LEES, M.; STANLEY, G. H. S. A simple method for the isolation and purification of total lipids from animal tissues. Journal of Biological Chemistry, v. 226, p. 497-509, 1957.

11 METCALFE, L. D.; SCHIMTZ, A. A.; PELKA, J. R. Rapid preparation of fatty acid esters from lipids for gas chromatographic analysis. Analytical Chemistry, v. 38, p. 514-515, 1966.

12 NEMEC, T.; JERNEJC, K.; CIMERMAN, A. Sterols and fatty acids of different Aspergillus species. FEMS Microbiology Letters, v. 149, p. 201-205, 1997.

13 OLIVEIRA, M. S.; BADIALE-FURLONG, E. Screening of antifungal and antimycotoxigenic activity of plant phenolic extracts. World Mycotoxin Journal, v. 1, p. 1-10, 2008.

14 PANDEY, A. Recent process developments in solid-state fermentation. Process Biochemistry, v. 27, n. 2, p. 109117, 1992.

15 PEN, X.; CHEN, H. Single cell oil production in solid-state fermentation by Microsphaepopsis sp. form steam-exploded wheat straw mixed with wheat bran. Bioresource Technology, v. 99, p. 3885-3889, 2008.

16 PITT, J. I.; HOCKING, A. D. Fungi and food spoilage. $2^{\text {nd }}$ ed. London: Blackie Academic \& Professional, 1997.

17 SILVEIRA, C. M.; BADIALE-FURLONG, E. Caracterização de compostos nitrogenados presentes em farelos fermentados em estado sólido. Boletim da SBCTA, v. 27, p. 805-810, 2007.

18 SILVEIRA, C. M.; OLIVEIRA, M. S.; BADIALE-FURLONG. E.; SOUZA-SOARES, L. A. Ácidos graxos em farelo de arroz: avaliação de procedimentos de extração e esterificação. In: CONGRESSO DE CIÊNCIAE TECNOLOGIADE ALIMENTOS, 20., 2006, Curitiba. Anais... Curitiba: TecArt, 2006. (CD-ROM).

19 STATISTICA for windows, Version 6.0. Tulsa: StatSoft, Inc., 2001.

20 STREDANSKY, M.; CONTI, E.; SALARIS, A. Production of polyunsaturated fatty acids by Pythium ultimum in solidstate cultivation. Enzyme and Microbial Technology, v. 23, p. 304-307, 2000.

21 STREDANSKY, M.; CONTI, E.; STREDANSKA, S.; ZANETTI, F. $\gamma$-linolenic acid production with Thamnidium elegans by solid-state fermentation on apple pomace. Bioresource Technology, v. 73, n. 1, p. 41-45, 2000.

22 ZHU, L. Y.; ZONG, M. H.; WU, H. Efficient lipid production with Trichosporon fermentans and its use for biodiesel preparation. Bioresouce Technology, n. 99, p. 7881-7885, 2008.

23 ZIINO, M.; LO CURTO, R. B.; SALVO, F.; SIGNORINO, D.; CHIOFALO, B.; GIUFFRIDA, D. Lipid composition of Geotrichum candidum single cell protein grown in continuous submerged culture. Bioresource Technology, n. 67, v. 1, p. 7-11, 1999. 